\title{
Contribution of pheromones processed by the main olfactory system to mate recognition in female mammals
}

\author{
Michael J. Baum* \\ Department of Biology, Boston University, Boston, MA, USA
}

\section{Edited by:}

Jorge A. Larriva-Sahd, Universidad

Nacional Autónoma de México,

Mexico

Reviewed by:

Jianzheng Zheng, University of New

Mexico, USA

Raúl G. Paredes, National University

of Mexico, Mexico

*Correspondence:

Michael J. Baum, Department of

Biology, Boston University,

5 Cummington St., Boston,

MA 02215, USA.

e-mail:baum@bu.edu
Until recently it was widely believed that the ability of female mammals (with the likely exception of women) to identify and seek out a male breeding partner relied on the detection of non-volatile male pheromones by the female's vomeronasal organ (VNO) and their subsequent processing by a neural circuit that includes the accessory olfactory bulb (AOB), vomeronasal amygdala, and hypothalamus. Emperical data are reviewed in this paper that demonstrate the detection of volatile pheromones by the main olfactory epithelium (MOE) of female mice which, in turn, leads to the activation of a population of glomeruli and abutting mitral cells in the main olfactory bulb (MOB). Anatomical results along with functional neuroanatomical data demonstrate that some of these $\mathrm{MOB}$ mitral cells project to the vomeronasal amygdala. These particular MOB mitral cells were selectively activated (i.e., expressed Fos protein) by exposure to male as opposed to female urinary volatiles. A similar selectivity to opposite sex urinary volatiles was also seen in mitral cells of the AOB of female mice. Behavioral data from female mouse, ferret, and human are reviewed that implicate the main olfactory system, in some cases interacting with the accessory olfactory system, in mate recognition.

Keywords: mouse, ferret, human, vomeronasal organ, hypothalamus

\section{INTRODUCTION}

Mice preferentially use olfactory as opposed to visual or auditory signals to locate potential mates (Brennan and Zufall, 2006). Pheromonal cues emitted from males' tear glands and/or preputial glands (excreted in urine) are thought to signal his presence, thereby attracting the female whereupon a pheromoneinduced facilitation of lordosis behavior occurs in response to the flank palpation provided by the male's mounting behavior. Mice of both sexes possess two detection systems for environmental odors. (1) The vomeronasal organ (VNO) has traditionally been considered to be the murine "pheromone detection system" (Tirindelli et al., 2009). VNO receptors located in the roof of the mouth extend axons to glomeruli located in the accessory olfactory bulb $(\mathrm{AOB})$ where they synapse onto the dendrites of $\mathrm{AOB}$ mitral cells which extend axons to the medial amygdala (MeA; part of the "vomeronasal amygdala") (Kevetter and Winans, 1981a). Neurons in the MeA project, in turn, to hypothalamic targets including the bed nucleus of the stria terminalis (BNST), the medial preoptic area (mPOA), and the ventromedial hypothalamus $(\mathrm{VMH})$. These brain areas are included in circuits that control females' proceptive (approach) and receptive (lordosis) behaviors (Blaustein and Erskine, 2002). (2) The main olfactory epithelium (MOE) has traditionally been thought to be the detection system for all non-pheromonal odorants present in the environment (Xu et al., 2000). Olfactory receptor neurons in the MOE extend axons to glomeruli located on the surface of the main olfactory bulb (MOB) where they synapse with dendrites of mitral cells that project extensively to diffuse target sites in the olfactory tubercle and in the anterior as well as the posterior piriform cortex (Sosulski et al., 2011). An early study (Kevetter and Winans, 1981b) demonstrated that a subset of MOB mitral cells also project to cortical amygdaloid nuclei ("olfactory amygdala"); however, more recent studies (Pro-Sistiaga et al., 2007; Kang et al., 2009; Thompson et al., 2012) show that there is a subpopulation of $\mathrm{MOB}$ mitral cells that project directly to the MeA ("vomeronasal amygdala"). This review summarizes the neuroanatomical and functional/behavioral experiments that established the existence of this latter MOB projection pathway and its role in the detection of volatile male pheromones in female mice. I will also review studies that point to a central role of the main olfactory system in the processing of pheromonal cues leading to mate recognition in female pigs and ferrets, and I will end by summarizing current evidence of the possible contribution of a putative male signaling pheromone to heterosexual attraction in women.

\section{INTERACTIVE ROLES OF THE MOE AND VNO IN MATE RECOGNITION AND SEXUAL BEHAVIOR IN FEMALE MICE}

Kimchi and co-workers (Kimchi et al., 2007) reported that female mice with a null mutation of the $\operatorname{Trp} 2 \mathrm{C}$ gene (initially reported to cause a total elimination of VNO function) failed to discriminate male from female conspecifics (Trp2C mutant females reportedly directed mounting behavior indiscriminately toward a castrated male and an estrous female). However, several other studies showed that surgical VNO destruction failed to disrupt the ability of female mice to discriminate body and/or urinary odors 
of male vs female or of testes-intact vs castrate male specifics (Lloyd-Thomas and Keverne, 1982; Keller et al., 2006b; Martel and Baum, 2009a). The Kimchi et al. study can be criticized on two grounds. First, it seems likely that some VNO neurons remain functional even after the Trp2C channel is knocked out: thus pregnancy block in response to pheromones from a strange (non-mating) male was retained in Trp2C female mice (Kelliher et al., 2006) even though surgical VNO removal has been shown to eliminate the pregnancy block otherwise induced in recently mated female mice that are exposed to urinary odors from a strange (non-mating) male (Lloyd-Thomas and Keverne, 1982). A recent study (Kim et al., 2011) showed that calcium activated chloride currents may also generate action potentials in murine VNO neurons. Second, Kimchi and co-workers (Kimchi et al., 2007) never directly assessed the ability of their Trp2C null mutant females to discriminate between pheromonal cues derived from male vs female conspecifics; instead females' motivation to direct mounts toward a castrated male vs an estrous female was assessed. By itself, this does not constitute a rigorous assessment of females' female-typical sexual motivation or of its signaling by sex-specific pheromonal cues. Systematic analysis of olfactory preferences in female mice (Keller et al., 2006b; Martel and Baum, 2009a) showed that surgical VNO destruction eliminated females' preference to investigate male vs female non-volatile urinary odors without disrupting their preference to approach volatile odor cues from a male. VNO destruction also dramatically reduced the capacity of female mice, when tested while in estrus, to display lordosis in response to the receipt of mounts from a male. A similar disruption of lordosis was seen in female mice given bilateral lesions of the AOB (Martel and Baum, 2009a). Likewise, in estrous female rats VNO lesions (Rajendren et al., 1990) as well as AOB lesions (Dudley and Moss, 1994) significantly reduced the expression of lordosis behavior. Further evidence of VNO involvement in the control of lordosis in mice comes from the work of Haga et al. (2010) who identified a pheromone secreted in male tears (exocrine gland-secreted pepide; ESP1). These workers showed that ESP1 stimulated immediate early gene expression in the female's VNO, after being detected by Vmn2r116 receptor. Further behavioral studies showed that application of ESP1 to WT females in estrus enhanced their lordosis behavior; however, no such facilitation was seen in females in which the Vmn24116 receptor was knocked out.

Several studies (Edwards and Burge, 1973; Keller et al., 2006a) showed that zinc sulfate lesions of the MOE eliminated the capacity of female mice to show a preference for volatile body odors emitted from male vs female or from testes-intact male vs castrated male conspecifics. These investigators also reported significant reductions in females' lordosis capacity after MOE lesions. Thus both the accessory and main olfactory inputs to the MeA may mediate the pheromonal facilitation of lordosis capacity in female mice. Results of a recent study (DiBenedictis et al., 2012) showed that bilateral lesions of the MeA (like lesions of the VNO, MOE, or AOB) also significantly diminished lordosis in ovariectomized females following priming with ovarian hormones. Thus central disruption of pheromonal inputs (e.g., ESP-1 males' tears; other yet to be determined male urinary volatiles) that are initially detected by either the $\mathrm{VNO}$ or the MOE are potentially as disruptive to the display of females' lordosis behavior as eliminating the ovarian sex hormones (e.g., after ovariectomy).

Early studies using female mice showed that females placed on soiled male bedding showed an increase in Fos and/or EGR1 expression in VNO sensory neurons (Halem et al., 1999, 2001; Kimoto et al., 2005) as well as in central target sites of these neurons including the AOB, the vomeronasal amygdala and hypothalamic regions including the BNST and VMH. These results have recently (Isogai et al., 2011) been confirmed and extended. In so far as subjects used in these studies had direct nasal contact with pheromones deposited in soiled bedding, it seems likely that the VNO played a central role in the pheromone detection Other early studies (Schaefer et al., 2001, 2002) showed, however, that urinary volatiles from male mice of different major histocompatibility complex (MHC) genotypes elicited significantly different profiles of $\mathrm{MOB}$ glomerular activation in females, as indexed by odor-induced expression of Fos in periglomerular cells surrounding activated glomeruli. The pheromone-activated glomeruli were concentrated in the ventral portion of the MOB. Numerous studies (Boehm and Zufall, 2006; Spehr et al., 2006) conducted over the past 30 years have shown that volatile MHC molecules as well as small peptide ligands for these molecules, contribute to individual mate recognition and mate choice in female mice. The detection of these individual MHC odortypes likely occurs after their detection by the MOE, since female mice from which the VNO was removed continued to successfully discriminate urinary volatiles from males of two MHC haplotypes (Wysocki et al., 2004). It is not known which of the $\sim 1000$ different classical olfactory receptor genes (Buck and Axel, 1991) expressed in the MOE detect MHC molecules. A second family of receptors (trace amineassociated receptors; TAARs) was recently found to be expressed in the MOE of mice (Liberles and Buck, 2006). These investigators also showed that trimethylamine is elevated in the urine of male vs female mice and is bound by mTAAR5-expressing cells. Liberles and Buck (2006) raised the possibility that trimethylamine, which like methylthio methanethiol (MTMT; see below) is a volatile component of male mouse urine, may serve as a signaling pheromone to attract males to female conspecifics. Other recent work (Lin et al., 2007) showed that many of the pheromone-responsive glomeruli in the MOB of both sexes are innervated by axons whose cell bodies in the MOE express the transient receptor potential channel M5 (TRPM5). It is not known whether TRPM5 expression occurs in subsets of MOE receptor neurons that express classical olfactory receptor proteins, TAARs, or both types of receptors. Electrophysiological recording from mitral cells in the ventral MOB of female mice revealed that a subset of these neurons were activated by male urinary volatiles (Lin et al., 2005). These same neurons in the female MOB were also reliably activated by MTMT which was also found to attract sexually experienced female mice in behavioral tests. In another study (Xu et al., 2005) functional magnetic resonance imaging (fMRI) was used to reveal glomerular activation in both the $\mathrm{MOB}$ and $\mathrm{AOB}$ of female mice in response to male urinary volatiles, with the MOB activation occurring slightly earlier than 
that in AOB. Slotnick and colleagues (Slotnick et al., 2010) suggested that the $\mathrm{VNO}$ responses to volatile pheromones typically are preceded by MOE detection which then leads the animal to make the nasal contact with a non-volatile pheromone, leading to VNO activation. Early work (Luo et al., 2003) showed used in vivo recordings from the mouse $\mathrm{AOB}$ in which neuronal activation was only seen after direct nasal contact with pheromonal stimuli.

The observation (Xu et al., 2005) that AOB activation (indexed by $\mathrm{fMRI}$ ) occurred in response to urinary volatiles, which are thought to be detected solely by the MOE as opposed to the VNO, was surprising. However, this outcome was confirmed and extended by a study (Martel and Baum, 2007) which compared the ability of urinary volatiles from male vs female mice to activate MOB glomeruli (indexed by Fos expression in the periglomerular cells) and augment Fos expression in AOB mitral and granule cells as well as in targets of VNO olfactory input in the vomeronasal amygdala and hypothalamus of gonadectomized (non-hormone treated) male and female mice. As predicted from the outcome of several above-mentioned studies, both male and female urinary volatiles activated multiple glomeruli located in the ventral MOB of both male and female subjects; the distribution of these activated glomeruli, while overlapping, was distinct in mice of both sexes exposed to male vs female urinary volatiles. In contrast to the MOB, only opposite-sex urinary volatiles stimulated Fos expression in mitral and granule cells of the AOB of each sex (i.e., female subjects showed AOB Fos responses to male urinary volatiles whereas male subjects showed AOB Fos responses to urinary volatiles from estrous females). In female subjects the selective Fos responsiveness of the AOB to male urinary volatiles extended to other forebrain targets of pheromone processing, including the vomeronasal amygdala and hypothalamus. By contrast, in male subjects exposure to either female or male urinary volatiles stimulated Fos expression in forebrain regions including the vomeronasal amygdala and hypothalamus. It is noteworthy that all of the $\mathrm{MOB}, \mathrm{AOB}$, and other forebrain Fos responses to urinary volatiles were absent in groups of gonadectomized female and male mice that 4 days earlier had received intranasal infusions of the toxic compound, zinc sulfate, which killed MOE sensory neurons. Zinc sulfate lesions of the MOE did not attenuate the ability of direct nasal contact with male urine to augment Fos expression in AOB mitral and/or granule cells. These results suggest that all observed Fos responses to urinary volatiles resulted from their detection by MOE, as opposed to VNO sensory neurons, and that there exists an input pathway whereby main olfactory signals reach the AOB.

Studies (Pro-Sistiaga et al., 2007; Kang et al., 2009) from rat and mouse point to the existence of a population of MOB mitral cells that extend axons directly to portions of the "vomeronasal (MeA) amygdala." These mitral cells are separate from the population of MOB mitral cells, described in the classic paper of Kevetter and Winans (1981b), which target subdivisions of the "olfactory amygdala," including the anterior cortical amygdala. In studies using female mice (Kang et al., 2009) dual labeling of the MOB (PHA-L) and AOB (Fluoro-Ruby) with anterograde tracers led to labeling of abutting superficial laminae of the ipsilateral MeA and MePD. In additional females, injection of the retrograde tracer, Cholera Toxin $\mathrm{B}(\mathrm{CTb})$ into the $\mathrm{MeA}$ led to retrograde labeling of a large number of $\mathrm{AOB}$ mitral cells as well as a restricted population of mitral cells located in the ventral and medial subdivisions of the MOB. In a functional study (Kang et al., 2009) exposure of ovariectomized, hormone-primed female mice to urinary volatiles from male, but not from female mice, significantly augmented the population of MeA projecting MOB mitral cells that co-expressed Fos protein. More recently, Thompson et al. (2012) found using both male and female mice that $\mathrm{MOB}$ glomeruli which receive synaptic inputs from MOE olfactory sensory neurons that express the cation channel TRPM5 (and which are thought to respond selectively to several different pheromones) are more likely to be innervated by an apical dendrite from MOB mitral cells that extend axons to the vomeronasal amgydala (MeA), although this overlap was not complete. Finally, evidence of a direct projection pathway of $\mathrm{MOB}$ mitral cells to the granule cells of the adjacent (ipsilateral) AOB has been provided in male rats (Larriva-Sahd, 2008).

We asked whether the MOB-MeA projection pathway passes information about male urinary volatiles on to the AOB, thereby accounting for our previous observation (Martel and Baum, 2007) that opposite-sex urinary volatiles (detected by the MOE, and not the VNO) augmented Fos expression in AOB mitral and granule cells? An anatomical study (Fan and Luo, 2009) used an anterograde tracer to show that axons extend from MeA neurons to innervate granule cells in the ipsilateral $\mathrm{AOB}$ of mice. We found (Martel and Baum, 2009b) that exposure to male, but not female, urinary volatiles stimulated the expression of Fos in the cell bodies of MeA neurons that were co-labeled with $\mathrm{CTb}$ which had been injected 1 week earlier into the ipsilateral AOB. As in our previous study (Martel and Baum, 2007) exposure to male, but not to female, urinary volatiles stimulated Fos expression in several brain regions, including the vomeronasal amygdala and several hypothalamic regions including the BNST, MPA, and VMH. Taken together, these data raised the possibility that opposite-sex (male) urinary volatiles are detected in the MOE by sensory neurons that express TRPM5. These neurons convey their inputs to a subset of MOB glomeruli where information about "maleness" is transferred directly to a subset of MOB mitral cells that target the MeA. The intregration of these main olfactory inputs and signaling from ovarian hormones (estradiol and progesterone) likely occurs in the posterior dorsal portion of the $\mathrm{MeA}$, as indicated by our recent finding (DiBenedictis et al., 2012) that bilateral lesions of the caudal (PD), but not the rostral, subdivision of the MeA disrupted the preference of estrous females to approach urinary volatiles from testes-intact vs castrated male mice.

It is widely agreed that even in the absence of previous nasal contact with male pheromonal cues, adult female mice are inherently motivated to investigate/make nasal contact with non-volatile urinary pheromones deposited by testes-intact adult males (Ramm et al., 2008). The attraction has been attributed to the presence of a particular major urinary protein (MUP), named darcin (Roberts et al., 2010), which is excreted in male mouse urine. This female-typical preference for male urine/darcin is hard wired, and likely depends on the absence of sex steroid signaling around the time of females' birth (which contrasts with an 
organizational action of perinatal testosterone and/or estrogenic metabolites of testosterone in the developing male hypothalamus) coupled with the later presence in females of estradiol signaling over a prepubertal period (P15-P25); (Brock et al., 2010, 2011). The strongest preference for male odors is expressed in adult cycling females on the night of proestrus, thanks to the central "activational" actions of estradiol and progesterone in the projection circuit that processes pheromonal cues. Additional studies (Ramm et al., 2008; Martinez-Garcia et al., 2009) suggested that female mice which had never had nasal contact or mating experience with a male showed no preference to seek out airborn urinary volatiles from male vs female conspecifics. By contrast, a robust preference for airborn (volatile) scents from males (vs castrated males or females) was seen in female mice that previously had experienced nasal contact with male urine or had mated with a male. This preference was strongest for volatile body odors from socially dominant males, provided females had previously had direct nasal access with the suite of odors deposited on cage bedding by dominant males (Mak et al., 2007; Veyrac et al., 2011). As already stated, female mice were strongly attracted to the volatile component of male urine, MTMT (Lin et al., 2005), a behavioral effect that was correlated with the ability of MTMT to augment electrical activity of MOB mitral cells in female mice. All of the females used in that study had received prior mating experience with males, thus it is not known whether naïve females which had not previously received either mating experience or nasal contact with male body parts/male urine would have been attracted to the putative volatile male urinary pheromone. Martinez-Ricos et al. (2007) also reported that nasal contact with soiled male bedding reliably served as a stimulus that established a learned conditioned place preference (CCP) response in female mice whereas access to volatiles emitted from soiled male bedding failed to establish a CCP. In this latter study, as in the other studies (Martinez-Ricos et al., 2008) that reported an absence of female preference for male vs female or male vs castrated male urinary or body volatile odorants the female subjects had been kept in a separate colony room from males beginning at the age of weaning. In these particular studies odor "naïve" female subjects were given behavioral tests in adulthood while ovary intact and at an unspecified stage of the estrous cycle. In another study (Ramm et al., 2008) female mice derived from wild caught parents were carefully prevented from experiencing contact with male body odorants until adulthood. In the absence of direct nasal experience with urine from a particular male, these females showed no preference to approach male vs female urinary volatiles. After nasal experience with a specific male, females later preferred to approach male vs female urinary odors, provided the male odor presented was from a specific male. Finally, Ramm et al. (2008) reported that they exposed all of their subjects to soiled bedding from an unfamiliar male for three consecutive days in order to bring their ovary-intact females into proestrous/estrous at the time their preference for male vs female urinary volatiles was assessed. No direct confirmation of the successful induction of proestrus/estrus (using vaginal smears) was carried out in this study, thus it remains a matter of speculation as to whether odor preferences were actually made while females were in an optimal hormonal condition to show a male-directed preference. Also, it is hard to argue that the subjects in this study were odor "naïve" given that direct nasal contact with soiled male bedding was reportedly used to bring all females in to proestrus/estrus at the time of testing.

In two recent studies (Martel and Baum, 2009a; DiBenedictis et al., 2012) my colleagues and I examined the preference of young adult female Swiss-Webster mice to approach volatile urinary odors from testes intact males vs either estrous females or castrated males. Although our females may have previously been exposed to volatile male body odors in the colony room, they had never had direct nasal access to such male odorants, nor had they had any mating experience prior to these studies. In both studies such naïve female subjects showed a significant preference to investigate volatile urinary odors from testes intact males vs estrous females (Martel and Baum, 2009a) or from testes intact males vs castrated males (DiBenedictis et al., 2012). In the former study the female subjects had been ovariectomized and treated chronically with a s.c. Silastic capsule releasing estradiol at the time odor preference was assessed. In the latter study, the female subjects had been ovariectomized, treated chronically with a s.c. Silastic capsule releasing estradiol, and given a s.c. injection progesterone 3-6h prior to the assessment of odor preference. Thus in both of our studies male odor "naïve" females (no prior nasal contact with male odors) showed a preference to investigate male urinary volatiles-findings that conflict with previous reports (Ramm et al., 2008; Martinez-Garcia et al., 2009) that female mice require prior nasal contact with male body or urinary odors in order for male urinary volatiles associated with non-volatiles (presumably detected by the female's VNO-AOBaccessory olfactory system). The absence of a preference for male urinary volatiles in the absence of previous nasal contact with male urine may reflect the non-estrous status at the time of behavioral testing in a large proportion of the ovary-intact females used in those previous experiments. It will be important in future studies to systematically assess the role of ovarian hormones in the expression of females' preference for male urinary (or general body) volatile odorants. The suggestion (Martinez-Garcia et al., 2009) that female mice attend to male urinary volatiles and find them rewarding only after a conditioning process in which these odors are paired with VNO detection of non-volatile male odorants that are processed via a hard-wired straight line pathway to the hypothalamus via the medial amygdala (Choi et al., 2005) is an attractive one. Indeed, there are several lines of neuroanatomical data that indirectly support this proposed mechanism. Thus inputs from the VNO are passed directly on to the $\mathrm{AOB}$ which, in turn, directly targets the MeA, followed by the hypothalamus with little or no input to higher olfactory cortical structures (Kevetter and Winans, 1981a; Kang et al., 2009). By contrast, MOB mitral cells that target the MeA invariably extend axon collaterals into the far reaches of anterior and posterior piriform cortex (Kang et al., 2011). The intermingling of $\mathrm{AOB}$ and $\mathrm{MOB}$ inputs to the $\mathrm{MeA}$, combined with parallel cortical processing of $\mathrm{MOB}$ inputs to the MeA may provide a substrate for the type of olfactory learning proposed by others (Ramm et al., 2008; Martinez-Garcia et al., 2009). It may also be, however, that ovarian hormones somehow obviate the need for this learning, leading females to express a preference for 
volatile male urinary odors in the absence of prior direct nasal contact with male urine. More research is needed to answer this question.

\section{EARLY EVIDENCE THAT FEMALE PIGS AND FERRETS USE THE MAIN OLFACTORY SYSTEM TO IDENTIFY OPPOSITE-SEX MATING PARTNERS}

The early work of Signoret and co-workers (Signoret, 1967, 1970) showed that female sows, when in estrus, were strongly attracted to the odor of androstenone, which is excreted in the saliva of boars that are in breeding condition. Androstenone both attracted estrous sows and facilitated their receptive, "standing" behavior when pressure was applied to the back by a mounting male. Dorries and coworkers showed that females detect low concentrations of androstenone more readily than male pigs (Dorries et al., 1995), and that the occlusion of the VNO ducts in female pigs failed to disrupt their detection/motivation to approach this odor (Dorries et al., 1997). These results suggested that the detection and processing of the volatile male steroid, androstenone, by the main as opposed to the accessory olfactory system was responsible for its actions as both a signaling and a releaser pheromone in the female pig. To date, nobody has directly tested this hypothesis in the pig.

Several studies from my laboratory established an obligatory role of the main, as opposed to the accessory system, in the detection of male pheromones that are required for females' sexual attraction to males. In the absence of prior mating experience, female ferrets that had been ovariectomized and treated in adulthood with estradiol preferred to approach volatile odors emitted from a breeding male vs and an estrous female that was anesthetized/placed in the goal boxes of an air-tight Y maze (Kelliher and Baum, 2001, 2002). The composition of volatiles emitted from anal scent gland secretions as well as urine is different in the two sexes (Zhang et al., 2005); presumably the female ferrets used in our behavioral experiments were responding to some combination of these volatile odorants. Female's preference for male volatiles persisted when the stimulus animals had previously had their anal scent glands surgically removed (Cloe et al., 2004), implying that other excretions (e.g., urine) emit volatiles that are sufficient to signal ferrets' sex to conspecifics. When we began studying mechanisms controlling mate recognition in ferrets there was controversy about the existence of a functional $\mathrm{VNO} / \mathrm{AOB}$ in ferret of either sex (Weiler et al., 1999). We confirmed the existence of a VNO in both male and female ferrets (Kelliher et al., 2001) and identified the projection target of VNO sensory neurons by identifying a small AOB located in the medial MOB that was selectively stained by soybean agglutinin-horseradish peroxidase. In a subsequent study (Woodley et al., 2004) surgical removal of the VNO from ovariectomized, estradiol-primed female ferrets failed to diminish their preference to approach volatile body odors emitted from an anesthetized male as opposed to an estrous stimulus female in Y maze tests. Likewise, following VNO removal female ferrets retained their ability to discriminate between odors released from either anal scent gland secretions or urine of male vs female ferrets, although the preference of VNO lesioned females to show prolonged nasal investigation of either 1-day-old male urine spots or blocks of wood previously soiled by a male ferret was lower than in sham-operated controls. We interpreted these findings to mean that $\mathrm{VNO}$ /accessory olfactory inputs in female ferrets, as in female mice (Martel and Baum, 2009a), function to maintain females in close proximity to non-volatile male pheromones previously deposited in the environment. Such VNO function may be important for ferrets living in the wild, in which the two sexes live apart except for the period of several weeks when the two sexes seek each other out/mate as the annual breeding season occurs in response to lengthening photoperiod (Moors and Lavers, 1981).

The persistence of female ferrets' ability to identify and approach male volatile odorants even after removal of the VNO implies that the main olfactory system plays a central role in mate recognition in this species. Two additional studies further support this view. First (Woodley and Baum, 2004), exposure to volatiles emitted from male and estrous female anal scent gland secretions led to the differential activation of glomeruli (indexed by the upreglation of Fos expression in periglomerular inter neurons) located mainly in the ventral $\mathrm{MOB}$ of estrous female ferrets, and the degree of activation by male anal scent gland odorants was not appreciably diminished after ovariectomy. The different profiles of MOB glomerular activation induced by volatile male and female anal scent gland odorants also occurred in male subjects; at the level of the MOB the glomerular responses to the same odors (e.g., male anal scent gland volatiles) was very similar in the two sexes. Earlier studies (Wersinger and Baum, 1997; Kelliher et al., 1998) suggested that the ability of male body odors to activate (stimulate Fos expression) the hypothalamus of male and female ferrets differs, an observation that correlates with the profound sex difference in the motivation of breeding ferrets to seek out volatile (and non-volatile) body odors from males. A second study (Kelliher and Baum, 2001) definitively implicated the main olfactory system in the detection/processing of volatile odors needed for heterosexual mate recognition. Estrous female ferrets were made permanently anosmic by infusing dental impression cement into both nares, thereby occluding the MOE. Anosmia was confirmed by showing that females given intra nares dental cement could not learn to use peppermint as a discriminative stimulus to locate food in $\mathrm{Y}$ maze tests. Also, following sacrifice at the end of the study, minimal Fos expression was seen in the mitral or granule cell layers of the MOB of anosmic females (no such reduction was seen in the AOB), and there was little periglomerlar expression of tyrosine hydoxylase in these animals. When confronted with a choice between volatile body odors from an anesthetized male vs estrous female, sham-occluded control female showed a strong preference to approach the male odors whereas no preference was seen in naresoccluded females. This was not surprising, given that only odor cues were available to allow anosmic females to make a choice (and they couldn't smell). The absence of a preference for males among anosmic females was more surprising in additional tests in which the sight and sound of male vs female stimulus animals was also available (male ferrets are twice as large as females; the two sexes also may emit different audible sounds). When confronted with a male in a small compartment, estrous females mated normally, even when they were anosmic. However, when 
subsequently retested for approach behaviors in the Y-maze, nares occluded (anosmic) females continued showing no preference to approach the male vs female stimulus animals, even when a brief behavioral interaction was allowed between the subject and the stimulus ferrets at the end of each Y-maze trial. These data showed that selective occlusion of the MOE (while apparently avoiding any disruption of VNO signaling) eliminated the capacity of estrous female ferrets to identify an appropriate male mating partner. Considered together with the demonstration (Woodley et al., 2004) that VNO removal failed to disrupt this capacity in female ferrets, these data establish the obligatory role of the MOE/main olfactory pathway in mate recognition in ferrets. As already explained, this outcome pointed to a similar mechanism that was subsequently found to be operative in female mice.

\section{IMPLICATIONS OF THE ANIMAL DATA FOR A ROLE OF THE MAIN OLFACTORY SYSTEM IN MATE RECOGNITION/ PSYCHOSEXUAL FUNCTION IN WOMEN}

There has been considerable controversy over the years about whether higher primates, including humans, communicate using pheromones (Wysocki and Preti, 2004). An early claim (Michael and Keverne, 1968) that sexual arousal/mating performance in male rhesus monkeys depended solely on the actions of "copulins," pheromones produced by the vagina of estradiol-primed females, was disputed (Goldfoot et al., 1978). However, the possibility remains that volatile odors emitted from the vagina modulate the motivation of male rhesus monkeys to approach females, depending on the phase of the female's menstrual cycle. There is also evidence (Baum et al., 1976, 1977) that progesterone reduces males' interest in females by counteracting the stimulatory action of estradiol on the vaginal production of pheromonal cues that signal attraction. However, results of other studies (Baum et al., 1978) showed that female stumptail monkeys would continue to be attractive to male conspecifics after all ovarian and adrenal steroids hormones were removed by combined ovariectomy and adrenalectomy. The same is true of post-menopausal women, who continue to be attractive to male partners, essentially in the absence of circulating sex hormones. Disagreement about whether pheromonal communication occurs in humans was further fueled by the belief that pheromonal communication in lower mammals depends solely on the existence of a functional VNO-accessory olfactory system. Genetic evidence (Kouros-Mehr et al., 2001) shows that VNO receptor genes in humans are non-functional, pseudogenes while anatomical experiments (Trotier et al., 2000) have shown that adult humans lack a functional VNO with sensory neurons that establish connections with an AOB (Meisami and Bhatnagar, 1998). The apparent absence of a functional VNO in humans led many skeptics to believe that the human lacks the detectors/circuits required for pheromonal communication. However, the results of many animal studies reviewed, above, suggest that this conclusion is unwarranted. Between-sex pheromonal communication clearly occurs in mice and ferrets after removal of the VNO. Thus the animal literature does not rule out the possibility of pheromonal communication in species such as humans which lack a functional VNO.
There are several examples in the literature of apparent male pheromonal actions in women. These include the ability of male underarm volatiles, when applied to the lips of women subjects, to accelerate the next LH pulse and improve mood ratings (Preti et al., 2003). A related example of human male pheromonal communication is the report (Jacob et al., 2002b) that women preferred to smell underarm odors of men that shared paternally inherited MHC alleles when them. This outcome is consistent with the report (Helgason et al., 2008) that women's fertility was highest when they mated with men who were third or fourth cousins. Thus in women, as in female mice (Barnard and Fitzsimons, 1989), reproductive success is maximized by breeding with distant relatives as opposed to totally unrelated males. Putative pheromonal cues from women may also influence neuroendocrine and behavioral functions in other women. Thus, Stern and McClintock (1998) reported that underarm odorants collected from women at different stages of the menstrual cycle advanced or delayed the timing of the preovulatory surge of luteinizing hormone in cycling female subjects. McClintock's group (Spencer et al., 2004) also reported that odorants collected from lactating women and their breast feeding infants augmented sexual motivation in women who smelled these odorants. These different examples of human pheromonal communication involve several classes of pheromones including primers, signalers, and releasers (McClintock, 2002). The mechanism whereby women (like female mice) identify the ideal mate may involve pheromonal communication mediated by the main olfactory system.

As already reviewed, the volatile steroid, androstenone, is a pheromone emitted from the saliva of male pigs which both signals the presence of a male in breeding condition and releases sexual activity, including approach and a receptive posture, in females. An evolving body of literature suggests that another, structurally related steroid, androstadienone (AND) is produced in underarms of men which may act as a pheromone that signals males' reproductive status to women. Polymorphisms in the olfactory receptor protein, OR7D4, were associated with variations among individual humans in their ability to detect AND and in their ratings of its pleasantness (Keller et al., 2007). There was no distinction between men and women in the number of people who reported being unable to smell AND or androstenone in this study; however, in previous report (Dorries et al., 1989) the ability to detect androstenone was more likely to diminish in boys than in girls after the age of puberty. An additional study (Zhuang et al., 2009) showed that there is considerable variation in OR7D4 sequences among old world monkeys and great apes, a result that is perhaps not surprising given the variation in sequence seen among humans. Despite the lack of uniformity in the expression of MOE olfactory receptor proteins that are capable of detecting AND, there are several studies suggesting that AND may attract women to men or attract gay men to other gay men. In a systematic comparison of rated preferences for different underarm odors, heterosexual women preferred the smell of underarm odors from heterosexual as opposed to gay men while gay men preferred underarm odors of other gay men (Martins et al., 2005). The authors raised the possibility that differences in the preference for the putative male underarm pheromone, AND, 
may underlie this profile of preferences, although this was not tested directly. A series of studies from Savic and co-workers used PET scanning to compare the profile of hypothalamic activation induced by application of AND to the upper lip of straight vs gay men and women as well as transgender persons. In an initial study (Savic et al., 2001) AND was found to induce hypothalamic activation in heterosexual women, but not in men. Gay men were subsequently found to show hypothalamic activation in response to AND that resembled that seen in heterosexual women (Savic et al., 2005); lesbian women failed to show hypothalamic PET responses to AND (Berglund et al., 2006), and in this respect resembled heterosexual men. In another study (Berglund et al., 2008) $46 \mathrm{XY}$ male to female transsexuals showed a significant hypothalamic PET response to AND that resembled the response seen in heterosexual women. The transsexual subjects used in that study stated that they had never received exogenous ovarian hormones in conjunction with their transition from male to female gender identity and role. This raises the question of whether fetal, organizational actions of testosterone in the male, as opposed to adult, activation effects of sex hormones, account for the observed sex differences in the AND-induced PET signal in the hypothalamus. Finally, in another study from the Savic group (Ciumas et al., 2009) significant AND-induced PET activation in the hypothalamus was seen in women with congenital adrenal hyperplasia and in whom fetal testosterone signaling was very likely higher than in the normal control women. This outcome calls into question the possible role of different fetal sex hormone signaling as the determinants of the reported sex differences/sexual orientation/gender identity effects on hypothalamic responses to AND. More research will be needed to resolve this issue. There is also a lingering question from these studies about the very high, potentially non-physiological, concentration of AND that was applied to subjects' upper lip.

Several studies have assessed the ability of AND to affect neuroendocrine as well as psychological functions related to mate recognition among women. Thus application of AND to the upper lip of heterosexual women significantly augmented salivary levels of cortisol (Wyart et al., 2007). Surprisingly, this effect of AND on cortisol secretion was correlated with a reported increase in sexual arousal while viewing an erotic film and with a reduction in the negative mood otherwise seen in a control condition. In another study (Cornwell et al., 2004) heterosexual women were asked to rate men's faces for potential long vs short term relationships, and while viewing the respective types of male face they were asked to rate the pleasantness of a series of 5 different odorants, including AND. There was a significant correlation between women's rating of men's faces for long-term relationships and positive pleasantness ratings of AND. The authors argued that visual and olfactory (AND) cues interact to signal male reliability for long term romantic relationships. Another study (Saxton et al., 2008) studied the possible interaction between visual and cognitive attributes of men and AND signaling on womens' ratings of male attractiveness in three different speed dating events. AND dissolved in a masking odor, clove oil, was applied to the upper lip as had been done in some earlier studies (Jacob and McClintock, 2000; Jacob et al., 2002a) which sought to avoid any conscious perception of the presence of AND when it was presented. Application of AND, as opposed to clove oil alone or water, caused women (whose sexual orientation was not explicitly determined, although most were presumably heterosexual) to give men they encountered in two of the three speed dating events significantly higher attractiveness ratings. While not a uniformly positive outcome, these results further point to a possible AND-dependent facilitation of the effects of visual and other cognitive cues on women's perception of men as attractive romantic partners. A somewhat different outcome was obtained in another recent study (Parma et al., 2012) in which eye movements of heterosexual women were monitored while they viewed male or female faces or several different inanimate objects. Women that were studied during the preovulatory, follicular (potentially fertile) phase of the menstrual cycle showed maximal attention (viewing time) directed toward female faces (vs male faces or inanimate objects), regardless of whether AND (dissolved in clove oil) or clove oil alone (control) was applied to the upper lip. By contrast, women studied during their luteal phase (low conception risk) preferred to watch female faces, provided they had received AND on the upper lip prior to the test. The authors argued that AND enhances intrasex competition for mates, although their case would have been stronger had they found that the ability of AND to focus women's attention on potential competitors was highest during the fertile phase of the menstrual cycle.

\section{CONCLUSION}

Over the past decade numerous papers using several different mammalian species have established an essential role for the MOE-MOB-main olfactory circuit in the detection and processing of male pheromonal cues that signal potential reproductive partners. In this review we have centered on the mouse, pig, and ferret as representative species in which this role of the main olfactory system in females' mate recognition clearly occurs. There is also some evidence for a similar role of the main olfactory system in the female hamster, another frequently used animal for studies of pheromone effects on mate recognition. Surgical destruction of the VNO in female hamsters failed to disrupt the ability to discriminate flank odors from individual male hamsters nor did VNO removal disrupt females' preference to investigate male as opposed to female odors (Petrulis et al., 1999; Johnston and Peng, 2000). To my knowledge, nobody has assessed the effects of MOE lesions on the preference of female hamsters for male vs female pheromones. Thus evidence of a definitive role of the main olfactory system in mate recognition in female hamsters is not yet forthcoming. The same is true of the female rat. Future studies, perhaps best carried out using mice, need to address several central questions: Is there a contribution of experience (either nasal contact with male non-volatile pheromones or mating experience itself) to the establishment of females' preference to seek out volatile male pheromones and what, if any, releaser function might such volatile male pheromones have on the expression of females' mating behavior? Are local circuits in the $\mathrm{MOB}$ and $\mathrm{AOB}$ of female mice differentially tuned to respond to male pheromones (either volatile or non-volatile pheromones, respectively) as opposed to semiochemicals from other females or from young pups? If so, is there a role of 
prepubertal ovarian hormones in the organization of femaletypical responses to pheromones that are detected by the main and/or accessory olfactory systems? Finally, further, definitive, experiments are needed to determine whether the putative human male pheromone, AND, facilitates the attractivity of potential

\section{REFERENCES}

Barnard, C. J., and Fitzsimons, J. (1989). Kin recognition and mate choice in mice: fitness consequences of mating with kin. Anim. Behav. 38, 35-40.

Baum, M. J., Everitt, B. J., Herbert, J., Keverne, E. B., and de Greef, W. J. (1976). Reduction of sexual interaction in rhesus monkeys by a vaginal action of progesterone. Nature 263, 606-608.

Baum, M. J., Keverne, E. B., Everitt, B. J., Herbert, J., and de Greef, W. J. (1977). Effects of progesterone and estradiol on sexual attractivity of female rhesus monkeys. Physiol. Behav. 18, 659-670.

Baum, M. J., Slob, A. K., de Jong, F. H., and Westbroek, D. L. (1978). Persistence of sexual behavior in ovariectomized stumptail macaques following dexamethasone treatment or adrenalectomy. Horm. Behav. 11, 323-347.

Berglund, H., Lindstrom, P., DhejneHelmy, C., and Savic, I. (2008). Male-to-female transsexuals show sex-atypical hypothalamus activation when smelling odorous steroids. Cereb. Cortex 18, 1900-1908.

Berglund, H., Lindstrom, P., and Savic, I. (2006). Brain response to putative pheromones in lesbian women. Proc. Natl. Acad. Sci. U.S.A. 103, 8269-8274.

Blaustein, J. D., and Erskine, M. S. (2002). "Feminine sexual behavior: cellular integration of hormonal and afferent information in the rodent brain," in Hormones and Behavior, eds D. W. Pfaff, A. P. Arnold, and E. Al (New York, NY: Academic Press), 139-214.

Boehm, T., and Zufall, F. (2006). MHC peptides and the sensory evaluation of genotype. Trends Neurosci. 29, 100-107.

Brennan, P. A., and Zufall, F. (2006). Pheromonal communication in vertebrates. Nature 444, 308-315.

Brock, O., Baum, M. J., and Bakker, J. (2011). The development of female sexual behavior requires prepubertal estradiol. J. Neurosci. 31, 5574-5578.

Brock, O., Douhard, Q., Baum, M. J., and Bakker, J. (2010). Reduced prepubertal expression of progesterone receptor in the hypothalamus of female aromatase knockout mice. Endocrinology 151, 1814-1821.

Buck, L., and Axel, R. (1991). A novel multigene family may encode odorant receptors: a molecular basis for odor recognition. Cell 65, 175-187.

Choi, G. B., Dong, H. W., Murphy, A. J., Valenzuela, D. M., Yancopoulos, G. D., Swanson, L. W., and Anderson, D. J. (2005). Lhx6 delineates a pathway mediating innate reproductive behaviors from the amygdala to the hypothalamus. Neuron 46, 647-660.

Ciumas, C., Linden Hirschberg, A., and Savic, I. (2009). High fetal testosterone and sexually dimorphic cerebral networks in females. Cereb. Cortex 19, 1167-1174.

Cloe, A. L., Woodley, S. K., Waters, P., Zhou, H., and Baum, M. J. (2004). Contribution of anal scent gland and urinary odorants to mate recognition in the ferret. Physiol. Behav. 82, 871-875.

Cornwell, R. E., Boothroyd, L., Burt, D. M., Feinberg, D. R., Jones, B. C., Little, A. C., Pitman, R., Whiten, S., and Perrett, D. I. (2004). Concordant preferences for opposite-sex signals? Human pheromones and facial characteristics. Proc. Biol. Sci. 271, 635-640.

DiBenedictis, B. T., Ingraham, K. L., Baum, M. J., and Cherry, J. A. (2012). Disruption of urinary odor preference and lordosis behavior in female mice given lesions of the medial amygdala. Physiol. Behav. 105, 554-559.

Dorries, K. M., Adkins-Regan, E., and Halpern, B. P. (1995). Olfactory sensitivity to the pheromone, androstenone, is sexually dimorphic in the pig. Physiol. Behav. 57, 255-259.

Dorries, K. M., Adkins-Regan, E., and Halpern, B. P. (1997). Sensitivity and behavioral responses to the pheromone androstenone are not mediated by the vomeronasal organ in domestic pigs. Brain. Behav. Evol. 49, 53-62.

Dorries, K. M., Schmidt, H. J., Beauchamp, G. K., and Wysocki, C. J. (1989). Changes in sensitivity to the odor of androstenone during adolescence. Dev. Psychobiol. 22, 423-435.

Dudley, C. A., and Moss, R. L. (1994). Lesions of the accessory olfactory

male sexual partners to women. A further analysis of the circuits that are activated by AND in men and women await the development of in vivo imaging methods with better resolution of amygdaloid and hypothalamic circuits than is possible with either PET or fMRI.

bulb decrease lordotic responsiveness and reduce mating-induced cfos expression in the accessory olfactory system. Brain Res. 642, 29-37.

Edwards, D. A., and Burge, K. G. (1973). Olfactory control of the sexual behavior of male and female mice. Physiol. Behav. 11, 867-872.

Fan, S., and Luo, M. (2009). The organization of feedback projections in a pathway important for processing pheromonal signals. Neuroscience 161, 489-500.

Goldfoot, D. A., Essock-Vitale, S. M., Asa, C. S., Thornton, J. E., and Leshner, A. I. (1978). Anosmia in male rhesus monkeys does not alter copulatory activity with cycling females. Science 199, 1095-1096.

Haga, S., Hattori, T., Sato, T., Sato, K., Matsuda, S., Kobayakawa, R., Sakano, H., Yoshihara, Y., Kikusui, T., and Touhara, K. (2010). The male mouse pheromone ESP1 enhances female sexual receptive behaviour through a specific vomeronasal receptor. Nature 466, 118-122.

Halem, H. A., Baum, M. J., and Cherry, J. A. (2001). Sex difference and steroid modulation of pheromoneinduced immediate early genes in the two zones of the mouse accessory olfactory system. J. Neurosci. 21, 2474-2480.

Halem, H. A., Cherry, J. A., and Baum, M. J. (1999). Vomeronasal neuroepithelium and forebrain Fos responses to male pheromones in male and female mice. J. Neurobiol. 39, 249-263.

Helgason, A., Palsson, S., Gudbjartsson, D. F., Kristjansson, T., and Stefansson, K. (2008). An association between the kinship and fertility of human couples. Science 319, 813-816.

Isogai, Y., Si, S., Pont-Lezica, L., Tan, T., Kapoor, V., Murthy, V. N., and Dulac, C. (2011). Molecular organization of vomeronasal chemoreception. Nature 478, 241-245.

Jacob, S., Garcia, S., Hayreh, D. and McClintock, M. K. (2002a). Psychological effects of musky compounds: comparison of androstadienone with androstenol and muscone. Horm. Behav. 42, 274-283.

Jacob, S., and McClintock, M. K. (2000). Psychological state and mood effects of steroidal chemosignals in women and men. Horm. Behav. 37, 57-78.

Jacob, S., McClintock, M. K., Zelano, B., and Ober, C. (2002b). Paternally inherited HLA alleles are associated with women's choice of male odor. Nat. Genet. 30, 175-179.

Johnston, R. E., and Peng, M. (2000). The vomeronasal organ is involved in discrimination of individual odors by males but not by females in golden hamsters. Physiol. Behav. 70, 537-549.

Kang, N., Baum, M. J., and Cherry, J. A. (2009). A direct main olfactory bulb projection to the 'vomeronasal' amygdala in female mice selectively responds to volatile pheromones from males. Eur. J. Neurosci. 29, 624-634.

Kang, N., Baum, M. J., and Cherry, J. A. (2011). Different profiles of main and accessory olfactory bulb mitral/tufted cell projections revealed in mice using an anterograde tracer and a whole-mount, flattened cortex preparation. Chem. Senses 36, 251-260.

Keller, A., Zhuang, H., Chi, Q., Vosshall, L. B., and Matsunami, H. (2007). Genetic variation in a human odorant receptor alters odour perception. Nature 449, 468-472.

Keller, M., Douhard, Q., Baum, M. J., and Bakker, J. (2006a). Destruction of the main olfactory epithelium reduces female sexual behavior and olfactory investigation in female mice. Chem. Senses 31, 315-323.

Keller, M., Pierman, S., Douhard, Q., Baum, M. J., and Bakker, J. (2006b). The vomeronasal organ is required for the expression of lordosis behaviour, but not sex discrimination in female mice. Eur. J. Neurosci. 23, 521-530.

Kelliher, K., and Baum, M. (2002). Effect of sex steroids and coital experience on ferrets' preference for the smell, sight and sound of conspecifics. Physiol. Behav. 76, $1-7$.

Kelliher, K. R., and Baum, M. J. (2001). Nares occlusion eliminates heterosexual partner selection without disrupting coitus in ferrets of both sexes. J. Neurosci. 21, 5832-5840.

Kelliher, K. R., Baum, M. J., and Meredith, M. (2001). The ferret's 
vomeronasal organ and accessory olfactory bulb: effect of hormone manipulation in adult males and females. Anat. Rec. 263, 280-288.

Kelliher, K. R., Chang, Y. M., Wersinger, S. R., and Baum, M. J. (1998). Sex difference and testosterone modulation of pheromone-induced NeuronalFos in the Ferret's main olfactory bulb and hypothalamus. Biol. Reprod. 59, 1454-1463.

Kelliher, K. R., Spehr, M., Li, X. H., Zufall, F., and Leinders-Zufall, T. (2006). Pheromonal recognition memory induced by TRPC2independent vomeronasal sensing. Eur. J. Neurosci. 23, 3385-3390.

Kevetter, G. A., and Winans, S. S. (1981a). Connections of the corticomedial amygdala in the golden hamster. I. Efferents of the "vomeronasal amygdala". J. Comp. Neurol. 197, 81-98.

Kevetter, G. A., and Winans, S. S. (1981b). Connections of the corticomedial amygdala in the golden hamster. II. Efferents of the "olfactory amygdala". J. Comp. Neurol. 197, 99-111.

Kim, S., Ma, L., and Yu, C. R. (2011). Requirement of calcium-activated chloride channels in the activation of mouse vomeronasal neurons. Nat. Commun. 2, 365.

Kimchi, T., Xu, J., and Dulac, C. (2007). A functional circuit underlying male sexual behaviour in the female mouse brain. Nature 448, 1009-1014.

Kimoto, H., Haga, S., Sato, K., and Touhara, K. (2005). Sex-specific peptides from exocrine glands stimulate mouse vomeronasal sensory neurons. Nature 437, 898-901.

Kouros-Mehr, H., Pintchovski, S., Melnyk, J., Chen, Y. J., Friedman, C., Trask, B., and Shizuya, H. (2001). Identification of nonfunctional human VNO receptor genes provides evidence for vestigiality of the human VNO. Chem. Senses 26, 1167-1174.

Larriva-Sahd, J. (2008). The accessory olfactory bulb in the adult rat: a cytological study of its cell types, neuropil, neuronal modules, and interactions with the main olfactory system. J. Comp. Neurol. 510, 309-350.

Liberles, S. D., and Buck, L. B. (2006). A second class of chemosensory receptors in the olfactory epithelium. Nature 442, 645-650.

Lin, D. Y., Zhang, S. Z., Block, E., and Katz, L. C. (2005). Encoding social signals in the mouse main olfactory bulb. Nature 434, 470-477.

Lin, W., Margolskee, R., Donnert, G., Hell, S. W., and Restrepo, D. (2007).
Olfactory neurons expressing transient receptor potential channel M5 (TRPM5) are involved in sensing semiochemicals. Proc. Natl. Acad. Sci. U.S.A. 104, 2471-2476.

Lloyd-Thomas, A., and Keverne, E. B. (1982). Role of the brain and accessory olfactory system in the block to pregnancy in mice. Neuroscience 7 , 907-913.

Luo, M., Fee, M. S., and Katz, L. C. (2003). Encoding pheromonal signals in the accessory olfactory bulb of behaving mice. Science 299 1196-1201.

Mak, G. K., Enwere, E. K., Gregg, C., Pakarainen, T., Poutanen, M., Huhtaniemi, I., and Weiss, S. (2007). Male pheromonestimulated neurogenesis in the adult female brain: possible role in mating behavior. Nat. Neurosci. 10, 1003-1011.

Martel, K. L., and Baum, M. J. (2007). Sexually dimorphic activation of the accessory, but not the main, olfactory bulb in mice by urinary volatiles. Eur. J. Neurosci. 26, 463-475.

Martel, K. L., and Baum, M. J. (2009a). Adult testosterone treatment but not surgical disruption of vomeronasal function augments male-typical sexual behavior in female mice. J. Neurosci. 29 7658-7666.

Martel, K. L., and Baum, M. J. (2009b). A centrifugal pathway to the mouse accessory olfactory bulb from the medial amygdala conveys genderspecific volatile pheromonal signals. Eur. J. Neurosci. 29, 368-376.

Martinez-Garcia, F., Martinez-Ricos, J., Agustin-Pavon, C., MartinezHernandez, J., Novejarque, A., and Lanuza, E. (2009). Refining the dual olfactory hypothesis: pheromone reward and odour experience. Behav. Brain Res. 200, 277-286.

Martinez-Ricos, J., Agustin-Pavon, C., Lanuza, E., and Martinez-Garcia, F. (2007). Intraspecific communication through chemical signals in female mice: reinforcing properties of involatile male sexual pheromones. Chem. Senses 32, 139-148.

Martinez-Ricos, J., Agustin-Pavon, C., Lanuza, E., and Martinez-Garcia, F. (2008). Role of the vomeronasal system in intersexual attraction in female mice. Neuroscience 153, 383-395.

Martins, Y., Preti, G., Crabtree, C. R. Runyan, T., Vainius, A. A., and Wysocki, C. J. (2005). Preference for human body odors is influenced by gender and sexual orientation. Psychol. Sci. 16, 694-701.
McClintock, M. K. (2002) "Pheromones, odors, and vasanas: the neuroendocrinology of socia chemosignals in humans and animals," in Hormones, Brain and Behavior, eds D. W. Pfaff, A. P. Arnold, A. M. Etgen, S. E. Fahrbach, and R. T. Rubin (San Diego, CA Elsevier), 797-870.

Meisami, E., and Bhatnagar, K. P. (1998). Structure and diversity in mammalian accessory olfactory bulb. Microsc. Res. Tech. 43, 476-499.

Michael, R. P., and Keverne, E. B. (1968). Pheromones in the communication of sexual status in primates. Nature 218, 746-749.

Moors, L. M., and Lavers, R. B. (1981). Movements and home range of ferrets at the Pukepuke lagoon, New Zealand. N.Z. J. Zool. 8, 413-423.

Parma, V., Tirindelli, R., Bisazza, A. Massaccesi, S., and Castiello, U. (2012). Subliminally perceived odours modulate female intrasexua competition: an eye movement study. PLoS ONE 7:e30645. doi: 10.1371/journal.pone.0030645

Petrulis, A., Peng, M., and Johnston, R. E. (1999). Effects of vomeronasa organ removal on individual odor discrimination, sex-odor preference, and scent marking by female hamsters. Physiol. Behav. 66, 73-83.

Preti, G., Wysocki, C. J., Barnhart, K. T., Sondheimer, S. J., and Leyden, J. J. (2003). Male axillary extracts contain pheromones that affect pulsatile secretion of luteinizing hormone and mood in women recipients. Biol. Reprod. 68, 2107-2113.

Pro-Sistiaga, P., Mohedano-Moriano, A., Ubeda-Banon, I., del Mar Arroyo-Jimenez, M., Marcos, P. Artacho-Perula, E., Crespo, C. Insausti, R., and Martinez-Marcos, A. (2007). Convergence of olfactory and vomeronasal projections in the rat basal telencephalon. J. Comp. Neurol. 504, 346-362.

Rajendren, G., Dudley, C. A., and Moss, R. L. (1990). Role of the vomeronasal organ in the male-induced enhancement of sexual receptivity in female rats. Neuroendocrinology 52, 368-372.

Ramm, S. A., Cheetham, S. A., and Hurst, J. L. (2008). Encoding choosiness: female attraction requires prior physical contact with individual male scents in mice. Proc. Biol. Sci. 275, 1727-1735.

Roberts, S. A., Simpson, D. M. Armstrong, S. D., Davidson, A. J., Robertson, D. H., McLean, L., Beynon, R. J., and Hurst, J. L. (2010). Darcin: a male pheromone that stimulates female memory and sexual attraction to an individual male's odour. BMC Biol. 8, 75 .

Savic, I., Berglund, H., Gulyas, B., and Roland, P. (2001). Smelling of odorous sex hormone-like compounds causes sex-differentiated hypothalamic activations in humans. Neuron 31, 661-668.

Savic, I., Berglund, H., and Lindstrom, P. (2005). Brain response to putative pheromones in homosexual men. Proc. Natl. Acad. Sci. U.S.A. 102, 7356-7361.

Saxton, T. K., Lyndon, A., Little, A. C., and Roberts, S. C. (2008). Evidence that androstadienone, a putative human chemosignal, modulates women's attributions of men's attractiveness. Horm. Behav. 54 597-601.

Schaefer, M. L., Yamazaki, K., Osada, K., Restrepo, D., and Beauchamp, G. K. (2002). Olfactory fingerprints for major histocompatibility complexdetermined body odors II: relationship among odor maps, genetics, odor composition, and behavior. J. Neurosci. 22, 9513-9521.

Schaefer, M. L., Young, D. A., and Restrepo, D. (2001). Olfactory fingerprints for major histocompatibility complex-determined body odors. J. Neurosci. 21, 2481-2487.

Signoret, J. P. (1967). Attraction de la femelle en oestrus par le male chez les porcins. Rev. Comp. Anim. 4, $10-22$.

Signoret, J. P. (1970). Reproductive behaviour of pigs. J. Reprod. Fertil. Suppl. (Suppl. 11), 105-117.

Slotnick, B., Restrepo, D., Schellinck, H., Archbold, G., Price, S., and Lin, W. (2010). Accessory olfactory bulb function is modulated by input from the main olfactory epithelium. Eur. J. Neurosci. 31, 1108-1116.

Sosulski, D. L., Bloom, M. L., Cutforth, T., Axel, R., and Datta, S. R. (2011) Distinct representations of olfactory information in different cortical centres. Nature 472, 213-216.

Spehr, M., Kelliher, K. R., Li, X. H. Boehm, T., Leinders-Zufall, T., and Zufall, F. (2006). Essential role of the main olfactory system in social recognition of major histocompatibility complex peptide ligands. $J$ Neurosci. 26, 1961-1970.

Spencer, N. A., McClintock, M. K., Sellergren, S. A., Bullivant, S., Jacob, S., and Mennella, J. A. (2004). Social chemosignals from breastfeeding women increase sexual motivation. Horm. Behav. 46, 362-370.

Stern, K., and McClintock, M. K. (1998). Regulation of ovulation by human pheromones. Nature 392, 177-179. 
Thompson, J. A., Salcedo, E., Restrepo, D., and Finger, T. E. (2012). Second order input to the medial amygdala from olfactory sensory neurons expressing the transduction channel TRPM5. J. Comp. Neurol. 520, 1819-1830.

Tirindelli, R., Dibattista, M., Pifferi, S., and Menini, A. (2009). From pheromones to behavior. Physiol. Rev. 89, 921-956.

Trotier, D., Eloit, C., Wassef, M., Talmain, G., Bensimon, J., Doving, K., and Ferrand, J. (2000). The vomeronasal cavity in adult humans. Chem. Senses 25, 369-380.

Veyrac, A., Wang, G., Baum, M. J., and Bakker, J. (2011). The main and accessory olfactory systems of female mice are activated differentially by dominant versus subordinate male urinary odors. Brain Res. 1402, 20-29.

Weiler, E., Apfelbach, R., and Farbman, A. I. (1999). The vomeronasal organ of the male ferret. Chem. Senses 24, 127-136.

Wersinger, S. R., and Baum, M. J. (1997). Sexually dimorphic processing of somatosensory and chemosensory inputs to forebrain luteinizing hormone-releasing hormone neurons in mated ferrets. Endocrinology 138, 1121-1129.

Woodley, S. K., and Baum, M. J. (2004). Differential activation of glomeruli in the ferret's main olfactory bulb by anal scent gland odours from males and females: an early step in mate identification. Eur. J. Neurosci. 20, 1025-1032.

Woodley, S. K., Cloe, A. L., Waters, P., and Baum, M. J. (2004). Effects of vomeronasal organ removal on olfactory sex discrimination and odor preferences of female ferrets. Chem. Senses 29, 659-669.

Wyart, C., Webster, W. W., Chen, J. H., Wilson, S. R., McClary, A., Khan, R. M., and Sobel, N. (2007). Smelling a single component of male sweat alters levels of cortisol in women. $J$. Neurosci. 27, 1261-1265.

Wysocki, C. J., and Preti, G. (2004). Facts, fallacies, fears, and frustrations with human pheromones. Anat. Rec. A Discov. Mol. Cell. Evol. Biol. 281, 1201-1211.
Wysocki, C. J., Yamazaki, K., Curran, M., Wysocki, L. M., and Beauchamp, G. K. (2004). Mice (Mus musculus) lacking a vomeronasal organ can discriminate MHC-determined odortypes. Horm. Behav. 46, 241-246.

$\mathrm{Xu}$, F., Greer, C. A., and Shepherd, G. M. (2000). Odor maps in the olfactory bulb. J. Comp. Neurol. 422, 489-495.

Xu, F., Schaefer, M., Kida, I., Schafer, J., Liu, N., Rothman, D. L., Hyder, F., Restrepo, D., and Shepherd, G. M. (2005). Simultaneous activation of mouse main and accessory olfactory bulbs by odors or pheromones. J. Comp. Neurol. 489, 491-500.

Zhang, J. X., Soini, H. A., Bruce, K. E., Wiesler, D., Woodley, S. K., Baum, M. J., and Novotny, M. V. (2005). Putative chemosignals of the ferret (Mustela furo) associated with individual and gender recognition. Chem. Senses 30, 727-737.

Zhuang, H., Chien, M. S., and Matsunami, H. (2009). Dynamic functional evolution of an odorant receptor for sex-steroid-derived odors in primates. Proc. Natl. Acad. Sci. U.S.A. 106, 21247-21251.

Conflict of Interest Statement: The author declares that the research was conducted in the absence of any commercial or financial relationships that could be construed as a potential conflict of interest.

Received: 17 April 2012; accepted: 19 May 2012; published online: 05 June 2012.

Citation: Baum MJ (2012) Contribution of pheromones processed by the main olfactory system to mate recognition in female mammals. Front. Neuroanat. 6:20. doi: 10.3389/fnana.2012.00020 Copyright (C) 2012 Baum. This is an open-access article distributed under the terms of the Creative Commons Attribution Non Commercial License, which permits non-commercial use, distribution, and reproduction in other forums, provided the original authors and source are credited. 